NOTAS

\title{
EXÉGESIS DE UN POEMA
} DE MALLARMÉ* Émile Noulet

A la nue accablante tu Base de basalte et de laves A même les échos esclaves Par une trompe sans vertu Quel sépulcral naufrage (tu Le sais, écume, mais y baves) Suprême une entre les épaves Abolit le mât dévêtu Ou cela que furibond faute De quelque perdition haute Tout l'abîme vain éployé

Dans le si blanc cheveu qui traîne

Avarement aura noyé

Le flanc enfant d'une sirène

* Traducción de Nora Pasternac, Centro de Lenguas-ITAM.

Nota: Con el pretexto de analizar un soneto de Mallarmé, Émile Noulet - crítico y literato francés-nos ofrece una excelente introducción a la estética del poeta hermético. Este artículo constituye una curiosidad historica: fue extraído de la revista Lettres Françaises, No 12 , abril de 1944, publicada en Buenos Aires. El subtítulo de la revista dice: "Cuadernos trimestrales de literatura francesa, editados a cargo de la revista SUR con la colaboración de los escritores franceses residentes en Francia y en el extranjero." En efecto,
[Ante la nube abrumadora silenciado

Base de basalto y de lavas

Entre los ecos esclavos

Por una trompeta sin virtud

Qué sepulcral naufragio (tú

Lo sabes, espuma, aunque burbujees)

Supremo uno entre los restos

Abolió el mástil desvestido

$\mathrm{O}$ aquello que furibundo falta

De alguna perdición alta

Todo el abismo vano desplegado

En el tan blanco cabello que cuelga

Avaramente habrá ahogado

El flanco infante de una sirena]

la publicación apareció en Buenos Aires durante la Segunda Guerra Mundial y se convirtió en uno de los órganos más importantes de los escritores franceses que se oponían a la ocupación alemana de su país. Fue dirigida por Roger Caillois, que debió permanecer en Argentina durante cinco años, pues la guerra y la ocupación de Francia lo sorprendieron en Buenos Aires mientras realizaba un ciclo de conferencias invitado precisamente por Victoria Ocampo que dirigía la revista SUR. Cuando regresó a París, se convirtió en un activo difusor de la literatura latinoamericana, a través de la colección "La Croix du Sud" 
NOTAS

El público francés no conoció este soneto, hermético si los hubo, sino mucho después de la muerte de Mallarmé, gracias a la edición que la Nouvelle Revue Française hizo de las Poésies Completes, en 1913.

Sin embargo, no estaba inédito. Había sido publicado por primera vez por la revista internacional Pan, editada por O. Julius Bierbaum, en Berlín, y ofrecía la foto del manuscrito en su número de abril-mayo de 1895 , acompañada de un dibujo del artista belga F. Khnopff. Apareció por segunda vez en la bella edición Deman (Bruselas, 1899), para la cual Mallarmé se tomó tanto trabajo durante el último año de su vida, escribiendo especialmente para esa edición su famosa bibliografía, aunque no llegó a verla aparecer. De todas maneras, el soneto data - en cuanto a su ejecución y a su elaboración - de una época en la que Mallarmé, en posesión de todos sus medios, no entrega a la publicación más que versos definitivos y no puntuados. Para traducirlo en términos claros no poseemos, pues, del auxilio de una primera versión ni del de ninguna controversia que una exégesis anterior hubiese suscitado. Es cierto que existen dos o tres variantes que se presentan en una reproducción posterior y sin garantías, en el libro de F. Calmettes,

que creó para la casa editorial Gallimard. A él se le debe en parte la notoriedad que Borges alcanzó en Europa a fines de la década de los 40 y durante las siguientes. Las aclaraciones entre corchetes me pertenecen. N.P.
Leconte de Lisle et ses amis (París, 1902). A pesar de todo señalémoslas, pues, verdaderas o falsas, son, con todo, significativas.

El verso 3 de la primera estrofa se escribe:

As même les échos esclaves[Tienes incluso los ecos esclavos]

$A s$ [tienes] no es un error del linotipista, sino de F. Calmettes mismo. Como se equivocó sobre el valor de $t u$ ["tú" y también participio pasado del verbo "taire": callar, silenciar] en el primer verso, buscó lógicamente en la misma estrofa el verbo que correspondería a ese supuesto pronombre personal; no pudo ver más que as; de eso dedujo que allí había un error de ortografía y restableció la $\$$ obligatoria. La s de Calmettes prueba que alguien al menos cayó en la trampa que Mallarmé había tendido suavemente al lector apresurado que, víctima de la ley del menor esfuerzo, fue conducido a atribuirle la misma naturaleza gramatical a los dos $t u$, ya que sobre el de la segunda estrofa no había ningún equívoco posible.

El segundo verso de la estrofa II, en el libro de Calmettes, se presenta de la manera siguiente:

Le sais écume mais y braves[Sabes que es espuma pero lo enfrentas]

Admitiendo aquí también la posibilidad de simples errores de imprenta, sigue siendo cierto que esas seudo-variantes tienen un sentido y que ese sentido, por erróneo que sea, trae consigo una enseñanza, aunque se presente como un efecto de rechazo. 
La sustitución de braves [enfrentas, desafías] en lugar de baves [burbujees, eches espumarajos, te babees, borbotees], no es contraria a la impresión superficial que causa la estrofa; desde el momento en que se trata de un naufragio y de la conciencia de perecer (evocados por las palabras sais [sabes], épave [restos de naufragio] y suprême [supremo]) se puede asociarles las nociones de resistencia y de valor, incluso inútiles, que despierta la palabra "desafiar" [braver].

Sin embargo, el error más interesante es la supresión de las comas antes y después de "espuma". Pues en la edición definitiva y revisada de Bruselas, que reproduce la de la Nouvelle Revue Française, esas dos comas son las únicas que Mallarmé conserva en este poema en el que, por otra parte, suprimió toda otra puntuación. Y la intención del escritor se percibe bien. Evidentemente ha querido que "espuma" sea tomado como un apóstrofe, y que no se fuera a cometer el error de convertir al término en la aposición del complemento como lo induce a creer el texto de Calmettes. Así Mallarmé, que prepara algunas trampillas para el distraído, se preocupa, en cambio, por socorrer a un lector más atento.

Una vez inutilizadas y desechadas esas variantes, para descifrar el poema sólo queda como guía la sintaxis. Gran cantidad de críticos muy ingeniosos admiten o suponen en sus comentarios que Mallarmé escribía mal el francés, y por ello se ven obligados a multiplicar los anacolutos, las silepsis y las elipsis, para extraer del texto una in- terpretación acorde con sus ideas preconcebidas. Pero si se parte de la opinión (que es la mía) de que el poeta no contravino jamás a las reglas exactas de la lengua, que probablemente conocía mejor que nosotros, es suficiente con seguir el poema paso a paso y a la letra, para culminar sin demasiado esfuerzo y $\sin$ trucos mágicos no ya en una "interpretación", sino modesta y solamente en una explicación.

Entonces, si hemos asistido a la gradual formación de su estética, si nos hemos habituado poco a poco a su vocabulario y a sus procedimientos, no estamos tan desprovistos de recursos al abordar este soneto que se encuentra al final de la evolución del poeta. Apoyándonos en una experiencia repetida, podemos dar con alguna certidumbre la transcripción real del poema.

Observemos en primer lugar que los cuartetos forman una sola frase sinuosa, arabesco cuyos movimientos violentos convienen a la representación de un naufragio.

Decidámonos luego, ya que la primera estrofa nopresenta ningún verbo en modo personal, a buscarle uno en la segunda [abolió: abolit] y a extraer la línea principal, dejando de lado los paréntesis impresos o mentales: "Qué sepulcral naufragio... abolió el mástil desvestido..., naufragio silenciado por una trompeta sin virtud... a la nube abrumadora".

Ahora podemos volver a los detalles y seguir el poema verso por verso. Ante la nube abrumadora silenciado... Se ve así aparecer la verdadera 
naturaleza y la relación de ese "tu" tan turbador: era simplemente la forma del participio pasado de "taire" [callar] y se refería a "naufragio" en el segundo cuarteto. Para que no nos equivocáramos, para obligarnos a un alto saludable, Mallarmé multiplicó las advertencias hasta hacer casi imposible la articulación por la sucesión difícil de las dentales te-tu; pero la simple inversión de una estrofa con la otra fue suficiente para imponer una pausa entre abrumadora y silenciado, pausà de la voz, que se vuelve sensible y normal, que hace inútil la puntuación superflua y justifica su omisión.

\section{El verso siguiente:}

Base de basalto y de lavas... que se podría poner entre dos guiones, sirve como aposición a "nube". De un efecto sensorial a la manera rimbaldiana, sus aliteraciones y la sucesión de sus diferentes $a$, completadas por las de accablante, imitan mejor que una descripción el peso negro de una nube baja.

\section{El verso:}

Entre los ecos esclavos... donde hay que admirar el bello y justo epíteto esclavos aplicado a ecos y que debe leerse a continuación del cuarto.

Por una trompeta sin virtud... No posee virtud la trompeta que debió anunciar el naufragio, gritarlo a los cuatro vientos, llenar los ecos con su sonido, iadvertir del naufragio a las nubes y al cielo! En lugar de eso, lo calló, y la triste derrota se consumó en el silencio y la ignorancia.
Qué sepulcral naufragio... he aquí el tema de los dos cuartetos y la base de la alegoría.

La presencia de los paréntesis: (tú

Lo sabes, espuma, aunque burbujees)... es la descripción concreta y moral de la espuma, único efecto y testigo del desastre; aunque su significación esté ligada al símbolo, tal vez sólo se justifica por la necesidad de las rimas difíciles en aves.

Supremo uno entre los restos... es una aposición de "rnástiles" y entonces podría escribirse también entre paréntesis o entre guiones; pero ison necesarias esas indicaciones gráficas? ya que es por demás evidente que, entre los restos, el mástil es el más alto, como lo dice el sentido latino de la palabra "supremo".

Abolió... ¿Es necesario insistir en la importancia de esa palabra en el vocabulario de Mallarmé? ¿Y recordar que la había heredado de Gérard de Nerval?

...el mástil desvestido... Desvestido de sus velas. En Salut [Salvación], Mallarmé designa con la misma metáfora la bella partida de los poetas: "La blanca preocupación de nuestra tela..."

Como los cuartetos, los dos tercetos no forman más que una sola frase tumultuosa cuyo sujeto es: Todo el abismo...

O aquello... implica una alternativa y anuncia otra hipótesis: ies un navío el que ha sido engullido sin apelación? o... Esas interrogaciones y la intención disyuntiva requieren entonces una pausa bastante larga después de "aquello". Por otra parte, el verso está 
singular y fuertemente cortado, como si se escucharan y esperaran los embates de los golpes del agua en el casco del navío en peligro. Porque "furibundo" se relaciona con "abismo", $y$ "falta" con el verso siguiente que se podría también considerar como un paréntesis dependiente a su vez de "furibundo".

falta - De alguna perdición alta... equivale a decir lo siguiente: A falta de una presa de valor, el abismo, el oceáno, furioso no habrá ahogado más que...

Todo el abismo vano desplegado... es junto con el primer verso de la estrofa siguiente : en el tan blanco cabello que cuelga, la descripción del mar desencadenado, cuya cólera, sin embargo, culmina sólo con la franja de espuma blanca en la cresta de las olas.

El flanco infante de una sirena... $\mathrm{El}$ mar embravecido, ¿qué habrá devorado? ¿Qué realidad? Ninguna. Una criatura quimérica. Ni siquiera. Un flanco... Todo el peso del cielo (primera estrofa), toda la violencia del mar (segunda y tercera estrofas), todas las fuerzas reunidas del viento y del agua han contribuido para aniquilar lo que apenas existe, menos que la forma entrevista de un mito naciente. Una vez más: poema desesperado que simboliza el sepultamiento de lo que no ha sido.

He aquí, entonces, determinado el tema preciso del soneto a partir del cual podemos inflarlo con todas las interpretaciones personales, ampliarlo a los símbolos más locos, relacionarlo con cualquier concepción místico-mágica. Su sentido primero está establecido; ofrecerá su resistencia propia a las significaciones segundas. Opondrá sus propias perspectivas puesto que vemos perfilarse detrás del soneto el sueño inmenso del poeta, la obra-síntesis que hubiera podido poner en jaque al azar, el Libro único, expresión total del mundo. Puesto que escuchamos, más patética aún, frente a la envergadura de semejante concepción, surgir la queja renovada de la impotencia creadora. 